\title{
Analysis of rhamnogalacturonan I fragments as elicitors of the defense mechanism in tomato fruit
}

\author{
Marīa Isabel Jiménez-Maldonado ${ }^{1}$, Martinn Ernesto Tiznado-Hernāndez ${ }^{1}$, Agustīn Rascón-Chu ${ }^{1}$, \\ Elizabeth Carvajal-Millán², Jaime Lizardi-Mendoza², and Rosalba Troncoso-Rojas ${ }^{1 *}$ \\ ${ }^{1}$ Centro de Investigación en Alimentación y Desarrollo, A.C. (CIAD, AC), Coordinación de Tecnología de Alimentos de Origen Vegetal, \\ Carretera a la Victoria km 0.6, C.P. 83304, Hermosillo, Sonora, México. *Corresponding author (rtroncoso@ciad.mx). \\ ${ }^{2}$ Centro de Investigación en Alimentación y Desarrollo, A.C. (CIAD, AC), Coordinación de Tecnología de Alimentos de Origen Animal, \\ Carretera a la Victoria km 0.6, C.P. 83304. Hermosillo, Sonora, México.
}

Received: 9 January 2018; Accepted: 4 June 2018; doi:10.4067/S0718-58392018000300339

\begin{abstract}
The rhamnogalacturonan I (RGI) is part of pectin plant cell wall, and currently there is scarce information about the elicitor effect of its fragments in the fruit defense mechanism. In this work, the effect of the fragments of RGI on the defense mechanism in tomato (Solanum lycopersicum L.) fruits was evaluated. Three fragments of RGI released from enzymatic degradation by RG lyase were characterized according to their physical-chemical and structural characteristics. Two of RGI fragments (F-1 and F-2) were selected and applied on tomato fruits during $48 \mathrm{~h}$. At different exposure times $(0,0.5,1,6$, 24 , and $48 \mathrm{~h}$ ) tomato samples were taken, and the enzymatic activity of chitinase was assessed by fluorometry, and $\beta-1,3-$ glucanase and peroxidase by spectrophotometry (UV-visible). The absorption bands determined by Fourier transform infrared (FT-IR) spectroscopy in the RGI fragments, was different concerning RGI no fragmented. The RGI had a molecular weight of $64 \mathrm{kDa}$ and an intrinsic viscosity of $40.9 \mathrm{~mL} \mathrm{~g}^{-1}$; while the molecular weight of F-1 and F-2 fragments were 20 and $16 \mathrm{kDa}$, and an average intrinsic viscosity of 27 and $26 \mathrm{~mL} \mathrm{~g}^{-1}$, respectively. The content of galacturonic acid decreased, and the neutral sugars increased concerning the time of enzymatic degradation. F-1 and F-2 fragments induced an increase in the level of $\beta$-1,3-glucanase activity in tomato fruits; however, an increase in the enzymatic activity of chitinase and peroxidase was observed after $0.5 \mathrm{~h}$ of exposure to F-2 fragment. It was concluded that the RGI fragments were structurally different from the RGI no fragmented and induced the natural defense mechanism of the tomato fruit.
\end{abstract}

Key words: Fragments of rhamnogalacturonan I, FT-IR, induction of PR proteins, light scattering, Solanum lycopersicum, sugar profile, tomato fruits.

\section{INTRODUCTION}

Tomato (Solanum lycopersicum L.) is one of the vegetables of higher production in the world (FAOSTAT, 2017); but due to its physiology and high water content it is highly perishable and easily damaged by pathogens, of which fungi are the main agents causing spoilage (Moss, 2008). Traditionally the synthetic fungicides have been used to control postharvest fruit diseases, but the fungal rot occurs despite the use of these synthetic compounds. This situation has led to the excessive and prolonged use of fungicides, which has raised concerns about possible health problems related to residual fungicides and also led to the development of resistant strains of fungi, which is one of the most critical issues in agriculture (Ribas et al., 2016). 
The current trend in the world demands the reduction of the use of synthetic fungicides; therefore, there is an increasing public and scientific interest towards the search for ecologically safer alternatives that guarantee the food safety. An alternative to reduce or inhibit the rot development is the induction of the natural defense mechanism in the fruit, in which the synthesis of secondary metabolites such as phenolic compounds are activated (Sánchez-Estrada et al., 2009), and modifications are made in the structural defenses (random creation of linkages between cell wall polymers, lignification, and suberization). It also increases the activity of pathogenesis-related enzymes such as chitinase and $\beta-1,3$-glucanase (Cota et al., 2007), induce the synthesis of reactive oxygen species, which play a significant role in defense against pathogens (Pandey et al., 2016). Such changes may limit the penetration and development of pathogens in host tissues, preventing or reducing fungal disease. However, the defense system of the plant is highly complex. The first interaction between plantpathogen occurs in the plant cell wall, which is a complex macromolecular structure that confers form and strength to the cell, and participates in the response of different types of stress (Caffall and Mohnen, 2009; Sénéchal et al., 2014).

Pectin is one of the components of the cell wall and consists of polysaccharides such as homogalacturonans, rhamnogalacturonans (RGI and RGII), and xylogalacturonans (Ho et al., 2016). The structure of these polysaccharides provides the pectin characteristics in the plant cell wall, such as the degree of porosity, level of hydration, as well as cell adhesion, which varies in response to the stress factor. Additionally, pectin is the component that plays an essential role in the physiology of the cell wall, and also in the response of the plant to pathogens attack (Harholt et al., 2010).

Previous studies have reported that fragments of pectic polysaccharides such as those derived from oligogalacturonanes and RGI may induce the defense mechanism in plants (Dinand et al., 1997; Boudart et al., 1998; Osorio et al., 2011). Fragments of pectin oligogalacturonides (OGs) with $\alpha$-1,4-linked have been used to induce the accumulation of phytoalexins in soy cotyledons. Also, they induce lignification in cucumber hypocotyls, expression of defense genes in Arabidopsis, and the production of reactive oxygen species in several plant species (Denoux et al., 2008). Boudart et al. (1998) reported a higher eliciting activity of the OGs fractions in the bean plant resistant to Colletotrichum lindemuthianum, which correlated with a higher content of galactose (Gal) and arabinose (Ara); and these sugars suggest the presence of RGI side chains. In another study, Dinand et al. (1997) obtained two tetrasaccharides of RGI from flaxseed (Linum usitatissimum L.), which showed a standard primary structure: $\alpha$-D-AGal $(1 \rightarrow 2)-\alpha$-L-Ram $(1 \rightarrow 4)-\alpha$-D-AGal- $(1 \rightarrow 2)-\alpha$-L-Ram. The application of these tetrasaccharides induced the activity of D-glucohydrolases ( $\beta$-D-xylosidase, $\alpha-1,4-\mathrm{D}$-galacturonase, laminarinase, and chitinase) in blackberry (Rubus fruticosus L.) cells.

These results suggest that the oligosaccharides of RGI induce the natural defense mechanism in plants. However, no published scientific information about the effect of the RGI fragments on the defense mechanism in tomato fruits has been found. Due to the above, the objective of the present study was to extract and characterize fragments of RGI and evaluate the effect of their application on the enzymatic activity of proteins related to pathogenesis in tomato fruit.

\section{MATERIALS AND METHODS}

\section{Preparation of rhamnogalacturonan I fragments}

Rhamnogalacturonan I (RGI) fragments were prepared according to McKie et al. (2001), and Wu and Mort (2014), with slight modifications. A sample of $150 \mathrm{mg}$ RGI from potato (Rhamnogalacturonan I (Potato), Megazyme, Bray, Ireland) was suspended in $300 \mathrm{~mL} 20 \mathrm{mM}$ Tris buffer $\mathrm{pH} 9.5$ with $1 \mathrm{mM} \mathrm{CaCl}_{2}$ under constant stirring. The sample was mixed with $55 \mathrm{U}$ of the enzyme RG lyase (Ramnogalacturonan Lyase 11A Cellvibrio japonicus; CjRg111A [PL11]; NZYTech, Ltd., Lisboa, Portugal), and incubated at $37^{\circ} \mathrm{C}$. An aliquot was taken at different incubation times $(0,0.5,1.0,1.5,2.0$, $2.5,3.0 \mathrm{~h}$, and subsequently every $3 \mathrm{~h}$ to $48 \mathrm{~h}$ ) and the absorbance was measured at a wavelength of $235 \mathrm{~nm}$ (Silva et al., 2016). The elicitor capacity of the fragments was preliminary assayed according to the peroxidase enzymatic activity, and the fragments with high values of peroxidase enzymatic activity were selected. These fragments were dialyzed on $10 \mathrm{kDa}$ (MWCO) membranes (Wu and Mort, 2014), lyophilized and kept in a desiccator until further analysis.

\section{Chemical and physicochemical analyses of the RGI fragments}

Fourier transform infra-red (FT-IR) spectroscopy. FT-IR spectra of RGI and RGI fragments were recorded using the attenuated total reflectance (ATR) technique in an infrared spectrophotometer with Fourier transform (Nicolet Instrument Corp., Madison, Wisconsin, USA). The samples were prepared to get $\mathrm{KBr}$ pellets ( $2 \mathrm{mg}$ sample $200 \mathrm{mg}^{-1} \mathrm{KBr}$ ). A KBr disk without sample was used as the blank. Spectra were recorded between 400 and $4000 \mathrm{~cm}^{-1}$ (Morales-Ortega et al., 2013). 
The molecular weight distribution was determined according to the technique reported by Morales-Ortega et al. (2013), with some modifications. Size exclusion high resolution liquid chromatography (SE-HPLC) was used at $38^{\circ} \mathrm{C}$, with a TSKgel (Polymer Laboratories, Church Stretton, UK) G5000 PWXL column $(7.8 \times 300 \mathrm{~mm}$, Tosoh Bioscience Supelco, San Francisco, Carolina California, USA). A sample of $20 \mu \mathrm{L}$ each RGI fragments were filtered through $0.45 \mu \mathrm{m}$ and injected into the SE-HPLC. The elution was isocratic at $0.6 \mathrm{~mL} \mathrm{~min}^{-1}$ with $0.1 \mathrm{M} \mathrm{LiNO}_{3}$. The detection was carried out using Waters 2414 refractive index detector. Molecular weights were estimated based on the calibration curve with pullulan as standards (P50 to P800).

Light-scattering molecular weight and intrinsic viscosity were determined using SE-HPLC at room temperature, with a system composed of a Shodex OH SB-G column (Showa Denko, Tokyo, Japan) followed in series with Shodex OHpak SB-804 HQ, and Shodex OHpak SB-804 HQ. $50 \mathrm{mM} \mathrm{NaNO}_{3}$ containing $0.02 \%$ (w/v) sodium azide at a flow rate of 0.5 $\mathrm{mL} \mathrm{min}^{-1}$ was used as the eluent. The samples were analyzed with the following detectors: (i) UV 1260 Infinity a 280 nm (Agilent Technologies, Santa Clara, California, USA); (ii) light scattering, (LS) (DAWN8+ (Wyatt, Santa Barbara, California, USA)); (iii) differential viscometer (DV) (ViscoStar II Wyatt), and (iv) differential refractometer (RI) Optilab T-rEX (RI) (Wyatt). The average weight of the molar masses, intrinsic viscosity, polydispersity and hydrodynamic radius were calculated and analyzed using ASTRA software version 6.1.2.84 (Wyatt). The differential of the refractive index ( $\mathrm{dn} /$ dc) used was $0.146 \mathrm{~mL} \mathrm{~g}^{-1}$ for RGI (Morris et al., 2010).

The neutral sugar profile in the RGI and its fragments was determined according to Blakeney et al. (1983) with modifications. Samples were hydrolyzed with $3 \mathrm{~N} \mathrm{H}_{2} \mathrm{SO}_{4}$ and inositol was added as an internal standard $\left(1 \mathrm{mg} \mathrm{mL}^{-1}\right)$. The mixture cooled, and $\mathrm{NH}_{3}$ was added. Aliquots were reduced with a $\mathrm{NaBH}_{4} / \mathrm{DMSO}$ solution. Subsequently, the samples placed at $35^{\circ} \mathrm{C}$ for $90 \mathrm{~min}$ and glacial acetic acid was added; the samples cooled on ice. After that, methyl imidazole with anhydrous acetic acid was added, the mixture cooled at room temperature for $20 \mathrm{~min}$, and chloroform was added. To remove the excess of acid, milli- $\mathrm{Q}$ water was added, and the lower phase was recovered, placing in $1 \mathrm{~mL}$ injection vials. For neutral sugar detection, a $0.32 \mathrm{~mm} \times 30 \mathrm{~m}$ BD225 (50\% cyanopropylphenyl-dimethylpolysiloxane, Teknokroma, Barcelona, Spain) column was used in an Agilent Technologies 6890N gas chromatograph, using hydrogen as the carrier gas. The oven and detector temperatures were 205 and $260{ }^{\circ} \mathrm{C}$, respectively, and the injection was carried out at $220{ }^{\circ} \mathrm{C}$. Identification of neutral sugars was performed on retention times of commercial standards: arabinose, ribose, galactose, xylose, rhamnose, and glucose (Sigma-Aldrich, St. Louis, Missouri, USA).

The content of galacturonic acid in the RGI and its fragments was determined according to Taylor (1993). Diluted sample in water $\left(100 \mu \mathrm{g} \mathrm{mL} \mathrm{m}^{-1}\right.$ ), were mixed with concentrated $\mathrm{H}_{2} \mathrm{SO}_{4}(98 \%)$ and $0.1 \% \mathrm{w} / \mathrm{v}$ carbazole (diluted in $100 \%$ ethanol). The tubes were incubated at $60{ }^{\circ} \mathrm{C}$ in a water bath for $1 \mathrm{~h}$ and then cooled in water. The absorbance of the pinkred color was measured at a wavelength of $530 \mathrm{~nm}$ at room temperature on a DR 500 UV-Visible spectrophotometer (Hach, Loveland, Colorado, USA). A calibration curve was performed with galacturonic acid at different concentrations, with an $\mathrm{R}^{2}$ of 0.99 . The results were expressed as $\mu \mathrm{g}$ galacturonic acid $\mathrm{mL}^{-1}$.

\section{Determination of elicitor activity of RGI fragments}

Pink tomato fruit 'Star' (color number four according to the color chart of USDA), without visible damage and with uniform size and firmness, was used. The fruits were bought in a local market located in Sonora, México, when they had $1 \mathrm{~d}$ after harvest. They were washed with $150 \mu \mathrm{LL}^{-1}$ sodium hypochlorite, rinsed and dried. The intact fruits were divided into three batches of 24 fruits each and each batch was exposed to different treatment.

Two solutions containing different RGI fragments (F-1 and F-2) at the concentration of $30 \mu \mathrm{M}$, were applied on the intact fruit surface and allowed to act for $48 \mathrm{~h}$ (Dinand et al., 1997). The fruits of the third batch were exposed to sterile water and were considered as control. After treatments, the intact fruits of each batch were placed in plastic boxes and maintained in a temperature-controlled chamber at $20{ }^{\circ} \mathrm{C}$ and $85 \% \mathrm{RH}$. Samples of the tomato pericarp were taken at different post-treatment times $(0,0.5,1,6,24$, and $48 \mathrm{~h})$ and lyophilized. Elicitor activity was determined at each sample according to the activity level of the enzymes $\beta$-1,3-glucanase, chitinase, and peroxidase. All the experiments were repeated twice with similar results.

Preparation of crude enzyme extracts and protein determination. A protein extract was prepared according to Cota et al. (2007) with modifications. A lyophilized sample $(0.2 \mathrm{~g})$ of tomato exposed to RGI fragments or control fruit was mixed with $10 \mathrm{~mL}$ of $100 \mathrm{mM}$ sodium acetate buffer ( $\mathrm{pH} 5.5$ ) containing $0.1 \% \beta$-mercaptoethanol, homogenized at $4{ }^{\circ} \mathrm{C}$ for 2 $\min$. The homogenate was filtered through organza fabric and centrifuged at $12000 \times \mathrm{g}$ for $15 \mathrm{~min}$ at $4{ }^{\circ} \mathrm{C}$. Protein was 
determined according to Bradford (1976) method using the protein assay reagent with bovine serum albumin (BSA) (BioRad, Hercules, California, USA) as a standard.

Total $\beta$-1,3-glucanase activity was determined using the 3,5-nitrosalicylic acid (DNS) method reported by Chaplin (1986) with modifications. The reaction mixture contained $50 \mu \mathrm{L}$ protein extract, mixed with $900 \mu \mathrm{L}$ sodium phosphate buffer, $50 \mathrm{mM}, \mathrm{pH} 7 ; 50 \mu \mathrm{L}$ laminarin substrate was then added. The mixture was incubated for $1.5 \mathrm{~h}$ at $40^{\circ} \mathrm{C}, 1000 \mu \mathrm{L}$ DNS reagent was added and left in a water bath for $5 \mathrm{~min}$ at $100^{\circ} \mathrm{C}$. Enzyme reactions were stopped by cooling the samples. Glucanase activity was determined by the release of reducing sugars using a DR 500 UV-Visible spectrophotometer with an absorbance at $540 \mathrm{~nm}$. Quantification was performed with a standard curve prepared with solutions of glucose at different concentrations, with an $\mathrm{R}^{2}$ of 0.99 . The specific activity of $\beta-1,3$-glucanase was defined as the amount of enzyme that catalyzed the formation of $1 \mathrm{mM}$ released glucose $\mathrm{min}^{-1} \mathrm{mg}^{-1}$ protein, and the results were reported as $\mathrm{U} \mathrm{mg}^{-1}$ protein.

Total chitinase activity was determined by fluorometry, according to Cota et al. (2007) with modifications. The reaction mixture contained $10 \mu \mathrm{L}$ protein extract, $5 \mu \mathrm{L}$ 4-methylumbelliferyl $\beta$-D- $N, N^{\prime}, N^{\prime}$ '-triacetylchitotrioside $1.3 \mu \mathrm{M}$ (4-MU, Sigma-Aldrich), and $35 \mu \mathrm{L} 50 \mathrm{mM}$ sodium phosphate buffer, $\mathrm{pH}$ 7. The reaction mixture was put in water bath for $5 \mathrm{~min}$ at $37{ }^{\circ} \mathrm{C}$. The reaction was stopped by immediately adding $150 \mu \mathrm{L} 0.2 \mathrm{M} \mathrm{Na}_{2} \mathrm{CO}_{3}$. The release of free 4-MU was measured by fluorescence spectroscopy with a UV fluorometer (TBS-380, Turner BioSystems, Sunnyvale, California, USA) using an excitation wavelength of $325 \mathrm{~nm}$ and emission of $446 \mathrm{~nm}$. Quantification was carried out with a calibration curve of 4-MU at different concentrations. The specific activity of the chitinase enzyme was defined as the release of $1 \mu \mathrm{mol}$ of 4-MU min ${ }^{-1} \mathrm{mg}^{-1}$ of protein. Results were reported in $\mathrm{U} \mathrm{mg}^{-1}$ protein.

Peroxidase activity assay was evaluated with a protein extract prepared with $0.2 \mathrm{~g}$ lyophilized tissue and mixed with 5

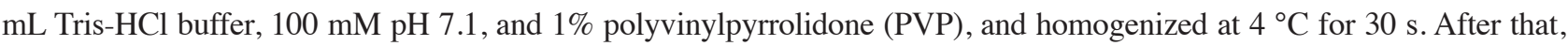
the mixture was centrifuged at $10000 \times \mathrm{g}$ for $20 \mathrm{~min}$ at $4{ }^{\circ} \mathrm{C}$. The supernatant (extract) was collected and stored at $-80{ }^{\circ} \mathrm{C}$ until the analysis. The total peroxidase activity was performed according to Flurkey and Jen (1978) with the following modifications. The reaction mixture was prepared with $2.6 \mathrm{~mL}$ of cold $100 \mathrm{mM}$ Tris- $\mathrm{HCl}$ buffer (pH 7.1), $0.25 \mathrm{~mL} 0.1 \mathrm{M}$ guaiacol, $0.1 \mathrm{~mL} 0.25 \%$ hydrogen peroxide and $50 \mu \mathrm{L}$ protein extract. The increase in absorbance $(470 \mathrm{~nm})$ was measured for $3 \mathrm{~min}$ in a DR $500 \mathrm{UV}$-Vis spectrophotometer. The specific activity of peroxidase was defined as the formation of $1 \mathrm{mmol}$ tetraguaiacol min $\mathrm{mg}^{-1}$ protein and the results were reported in $\mathrm{U} \mathrm{mg}^{-1}$ protein. All determinations were repeated thrice.

\section{Statistical analysis}

The elicitor effect of two different RGI fragments on the enzymatic activities in tomato fruits, and the time at which a greater response is induced when applying the RGI fragments, both effects were studied by a completely randomized design with a factorial arrangement of two factors. Factor A were the RGI fragment treatments with three levels (control, F-1, F-2), and the B factor were the sampling times after the treatment with six levels $(0,0.5,1,6,24$, and $48 \mathrm{~h})$. An ANOVA was performed by general linear model (GLM) analyzing the fixed factor treatments (RGI fragments) and sampling time, as well as the interaction of both factors. For means comparison, Tukey's multiple range test $(\mathrm{P} \leq 0.05)$ were performed. All statistical analyses were carried out using NCSS software package (2007; NCSS, Kaysville, Utah, USA).

\section{RESULTS}

\section{Extraction and characterization of RGI}

Figure 1 shows the Fourier transform infrared (FTIR) spectrum of RGI no fragmented (RGI nf), and RGI fragments obtained after 6,12 , and $24 \mathrm{~h}$ of enzymatic degradation by RGL. In the spectrum of RGI nf, the presence of the absorption bands between $3300-3500 \mathrm{~cm}^{-1}$ is associated with $\mathrm{OH}$ bonds, while between $2900-3000 \mathrm{~cm}^{-1}$ could be assigned to $\mathrm{CH}$ bonds. Also, the absorption band between $1500-1650 \mathrm{~cm}^{-1}$ could be attributed to the double bond associated with the carboxyl group $(\mathrm{C}=\mathrm{O})$, between the $897-1158 \mathrm{~cm}^{-1}$ the $\mathrm{C}-\mathrm{OH}$ bond with shoulders in both sides of the band and which may be related to the antisymmetric $\mathrm{C}$-O-C bonds (stretching mode of $\beta$-glucosidic bonds). No band was observed in the region of $1750 \mathrm{~cm}^{-1}$, corresponding to the absorption band of the $\mathrm{C}=\mathrm{O}$ double bond associated with the esters, suggesting that the RGI nf is demethyl-esterified. Differences in the spectra of the RGI fragments concerning RGI nf were observed, but similar spectra among the RGI fragments were recorded. A more pronounced absorbance band was observed in the $2950 \mathrm{~cm}^{-1}$ region, which is attributed to the stretching of the $\mathrm{C}-\mathrm{H}$ atoms associated with the $\mathrm{CH}_{2}$ groups. Also, an 
Figure 1. Fourier transform infra-red (FT-IR) spectrum of rhamnogalacturonan I (RGI) no fragmented (nf) and its fragments obtained by enzymatic degradation of RG lyase during 6, 12, and $24 \mathrm{~h}$ of incubation. Some functional groups are marked by arrows.

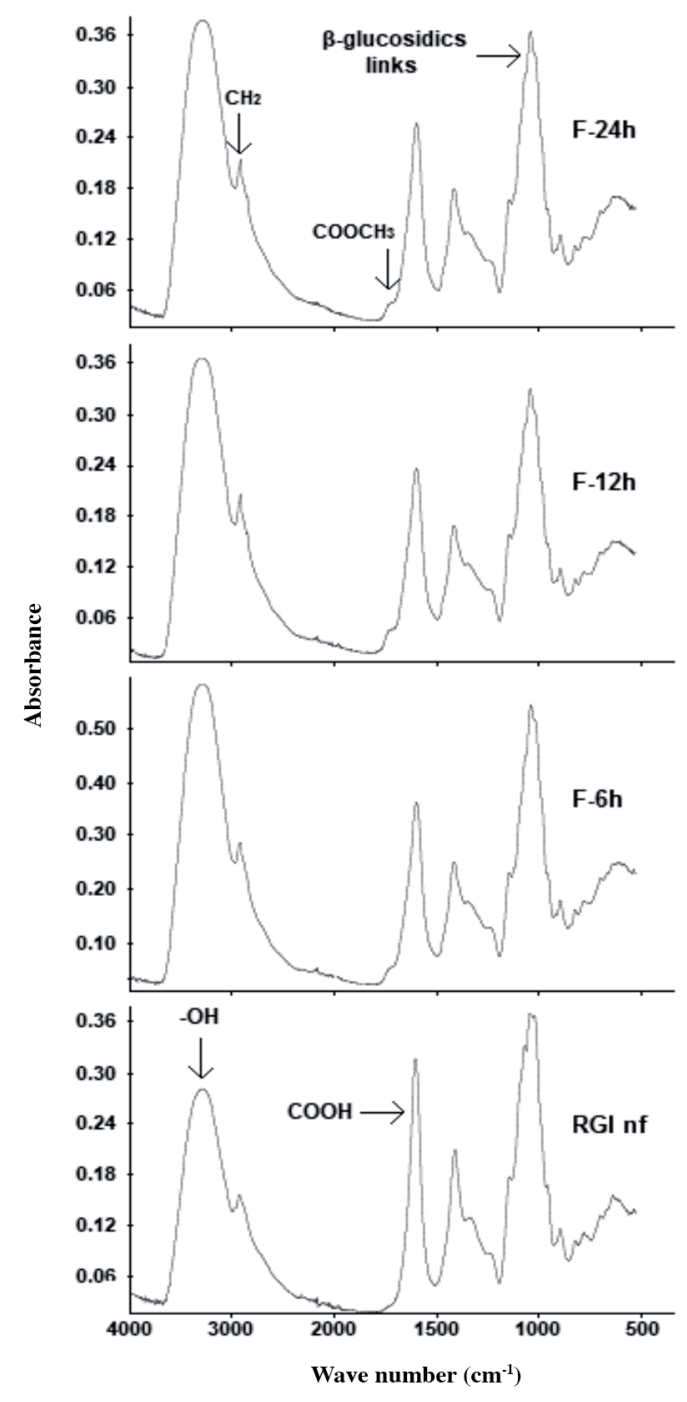

absorbance band was observed in the $1750 \mathrm{~cm}^{-1}$ region, which suggests a low degree of methyl esterification of RGI fragments. Also, the height of the absorbance band recorded in the $1500-1650 \mathrm{~cm}^{-1}$ region that is associated with carboxyl groups decreased to that observed in the RGI nf.

\section{Molecular weight distribution of RGI}

The profile of molecular weight distribution RGI nf is shown in Figure 2. A major peak was observed at the retention times between 14 and $15.5 \mathrm{~min}$, a region corresponding to the small molecular weights (110-50 kDa). Also, a shoulder to the left of the principal peak was also recorded at a retention time of 12.0-13.6 min with estimated molecular weights between 400 and $200 \mathrm{kDa}$. According to this elution pattern, RGI is considered to be polydisperse with an apparent molecular weight in a broad range of 400-50 kDa. On the base of the major peak, an approximate weight of $64 \mathrm{kDa}$ is estimated.

\section{Light-scattering molecular weights and intrinsic viscosity}

Table 1 shows the results of light-scattering molecular weights $(\mathrm{Mw})$, intrinsic viscosity $\left([\eta]_{\mathrm{w}}\right)$, polydispersity $(\mathrm{P})$, and hydrodynamic radius $\left(\mathrm{Rh}(\mathrm{v})_{\mathrm{w}}\right)$; as well as the constants $\mathrm{K}$ and $\alpha$ generated by the different characteristics of the polymer. 
Figure 2. Profile of molecular weight distribution of rhamnogalacturonan I (RGI) of potato (no fragmented) by size exclusion high performance liquid chromatography (SE-HPLC). In the upper side, the pullulans are shown as molecular weight markers $(\mathrm{kDa})$ and as a calibration scale.

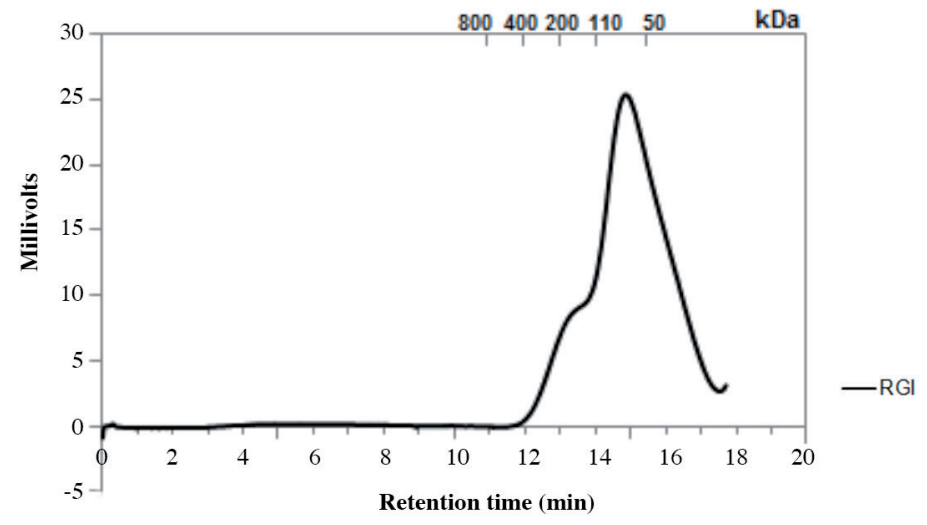

Table 1. Molecular properties of the rhamnogalacturonan I no fragmented (RGI nf) of potato and fragments obtained by enzymatic degradation of the RG lyase.

\begin{tabular}{lcccccc}
\hline Sample & $\mathrm{M}_{\mathrm{w}}$ & {$[\eta]_{\mathrm{w}}$} & $\mathrm{P} \mathrm{M}_{\mathrm{w}} / \mathrm{M}_{\mathrm{n}}$ & $\mathrm{Rh}(\mathrm{v})_{\mathrm{w}}$ & $\mathrm{K}$ & $\alpha$ \\
\hline & $\mathrm{kDa}$ & $\mathrm{mL} \mathrm{g}^{-1}$ & & $\mathrm{~nm}$ & $\mathrm{~mL} \mathrm{~g}^{-1}$ & \\
RGI nf & 53 & 41 & 1.6 & 6.5 & 0.30 & 0.47 \\
F-6 h & 29 & 29 & 1.5 & 4.8 & 0.14 & 0.54 \\
F-12 h & 20 & 27 & 1.4 & 4.3 & 0.11 & 0.57 \\
F-24 h & 16 & 26 & 1.5 & 3.9 & 0.22 & 0.50 \\
\hline
\end{tabular}

Mw: Average molecular weight, $[\eta]_{\mathrm{w}}$ : intrinsic viscosity, $\mathrm{P}$ : polydispersity, $\mathrm{Rh}(\mathrm{v})_{\mathrm{w}}$ : hydrodynamic radius, $\mathrm{Mn}$ : number average molar mass (data not shown), $\mathrm{K}$ and $\alpha$ constants.

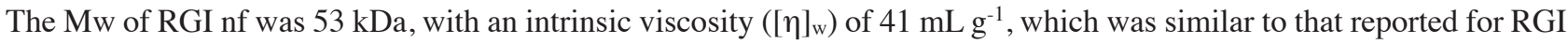
of the beet $\left(36 \mathrm{~mL} \mathrm{~g}^{-1}\right)$. Previous studies in beet indicate that the $[\eta]_{\mathrm{w}}$ is relatively low for a molecule with weight average molar mass of $188000 \mathrm{~g} \mathrm{~mol}^{-1}$. Also, that study may suggest that this RGI has a more compact conformation (Morris et al., 2010) compared to that of potato of the present study.

The Mw of the RGI nf was $60 \%-70 \%$ higher than the Mw of RGI fragments, as expected by the time of enzymatic treatment. The hydrodynamic radius $\left(\mathrm{Rh}(\mathrm{v})_{\mathrm{w}}\right)$ of the molecules formed in solution decreased 1.6-fold with respect to the fragment released $24 \mathrm{~h}$ after enzymatic degradation. On the other hand, the experimental constants $\mathrm{K}$ and $\alpha$ indicate that the polymer-solvent interaction of the fragments (F-6, 12 and $24 \mathrm{~h}$ ) could be in a random coil conformation (Sousa et al., 2015).

\section{Neutral sugars profile and content of galacturonic acid}

Table 2 shows the main neutral sugars and the content of galacturonic acid recorded in RGI nf and its fragments. The first neutral sugars detected in RGI of potato were rhamnose, galactose, and mannose. Other neutral sugars such as glucose, arabinose, and xylose were present but at low concentrations (below 1.7\%). In the RGI nf, the high content of galactose $(10 \%)$ suggests the presence of galactose side chains and a lower proportion of mannans (1\% mannose) and arabinoxylans (Ara/Xyl ratio 0.65). In the RGI fragments, the neutral sugars content increases and the content of galacturonic acid decreases. However, it can be seen that F-24 h fragment does not follow the same pattern as the other RGI fragments, regarding AGal decrease. This result may be due to the incubation time; it is possible that at longer incubation time, the polymer has been unfolded leaving exposed the sites of action of RGLase, which catalyzes the degradation of the $\alpha-1,4$ glycosidic linkage of the RGI main chain by a mechanism of $\beta$-elimination. Also, the increase in the content of galacturonic acid may be due to the RGI being degraded by the enzyme; smaller fragments are generated, which are not necessarily evenly distributed. This statement is supported with the results shown in Table 1 , where it is observed that the molecular weight decreases with respect to the time of enzymatic degradation, but the polydispersity increases slightly in the last fragment. 
Table 2. Composition of neutral sugars and galacturonic acid content of rhamnogalacturonan I no fragmented (RGI nf) and its fragments (6, 12, and $24 \mathrm{~h}$ of enzymatic degradation).

\begin{tabular}{lcccccccc}
\hline & \multicolumn{7}{c}{ Composition of sugars (\% by weight) } \\
\cline { 2 - 9 } Sample & GalA & Rha & Gal & Glc & Ara & Xyl & Man & Others \\
\hline RGI nf & 71.1 & 5.7 & 10.6 & 0.35 & 0.36 & 0.55 & 1.3 & 10.04 \\
F-6 h & 56.7 & 7.6 & 12.5 & 0.62 & 0.34 & 0.66 & 1.5 & 20.08 \\
F-12 h & 28.5 & 7.7 & 12.7 & 0.76 & 0.35 & 0.63 & 1.7 & 47.66 \\
F-24 h & 45.1 & 8.0 & 13.0 & 0.76 & 0.35 & 0.64 & 1.6 & 30.55 \\
\hline
\end{tabular}

GalA: galacturonic acid, Rha: rhamnose, Gal: galactose, Glc: glucose, Ara: arabinose, Xyl: xylose, Man: mannose. The sugars were compared with the retention times of the commercial standards.

\section{Elicitor effect of RGI fragments on the defense proteins in tomato fruit}

Results from preliminary tests in our laboratory showed that RGI fragments obtained from enzymatic degradation by rhamnogalacturonan lyase during the incubation times: $12 \mathrm{~h}$ (F-1), and $24 \mathrm{~h}$ (F-2), showed a higher peroxidase activity in tomato fruits. Therefore, both fragments were chosen to evaluate their effect on the induction of the defense proteins in tomato fruit.

Figure 3 shows the results of the specific activity of the enzyme $\beta$-1,3-glucanase in tomato fruit exposed to the fragments of RGI (F-1 and F-2), during $48 \mathrm{~h}$. It can be seen that after $6 \mathrm{~h}$ exposure both fragments induced a significant increase in the level of enzymatic activity, which was 2 and 1.6 times over the control, respectively. After that, the level of enzymatic activity decreases substantially and remains constant until $48 \mathrm{~h}$. Nonsignificant differences were observed in the level of enzymatic response induced between the two RGI fragments, probably because the characteristics and properties of the polymers were similar.

The results of the effect of the RGI fragments on the specific activity of chitinase in tomato fruits during $48 \mathrm{~h}$ are shown in Figure 4. An early induction of chitinase activity can be observed in comparison with glucanase activity. After $0.5 \mathrm{~h}$ of exposure, the F-1 and F-2 fragments induced a significant increase of chitinase activity (1.2 and 2.3-fold respectively), with respect to the control at the same exposure time. After this time, the enzyme activity decreased in all the treatments, but after $48 \mathrm{~h}$ an increase in the level of chitinase activity was observed, mainly in fruits exposed to the F-1 treatment. A similar behavior has been previously reported for pectin fragments of bean seedlings (Boudart et al., 1998).

Figure 5 shows the results of the effect of the RGI fragments on the level of peroxidase activity in tomato fruit during 48 $\mathrm{h}$ at $20^{\circ} \mathrm{C}$. As shown in the figure, the F-2 fragment induced an early and significant increase (1.8 times over the control) in the level of peroxidase activity after $0.5 \mathrm{~h}$ of exposure. After that, a fluctuation in activity levels was observed in all treatments. At the end of the evaluation $(48 \mathrm{~h})$, both fragments elicited a significant increase in the level of peroxidase activity. These results agree with those reported by Camejo et al. (2012), which found an early induction of peroxidase activity in alfalfa roots after $0.5 \mathrm{~h}$ of exposure to oligogalacturonic acids.

Figure 3. Effect of two fragments of potato rhamnogalacturonan I (RGI) (F-1 and F-2) on $\beta$-1,3-glucanase activity in tomato fruits stored for $48 \mathrm{~h}$ at $20{ }^{\circ} \mathrm{C}$ and $85 \% \mathrm{RH}$. Each point represents the mean of 3 fruits and vertical lines the standard deviation. Different letters indicate significant differences $(p \leq 0.05)$.

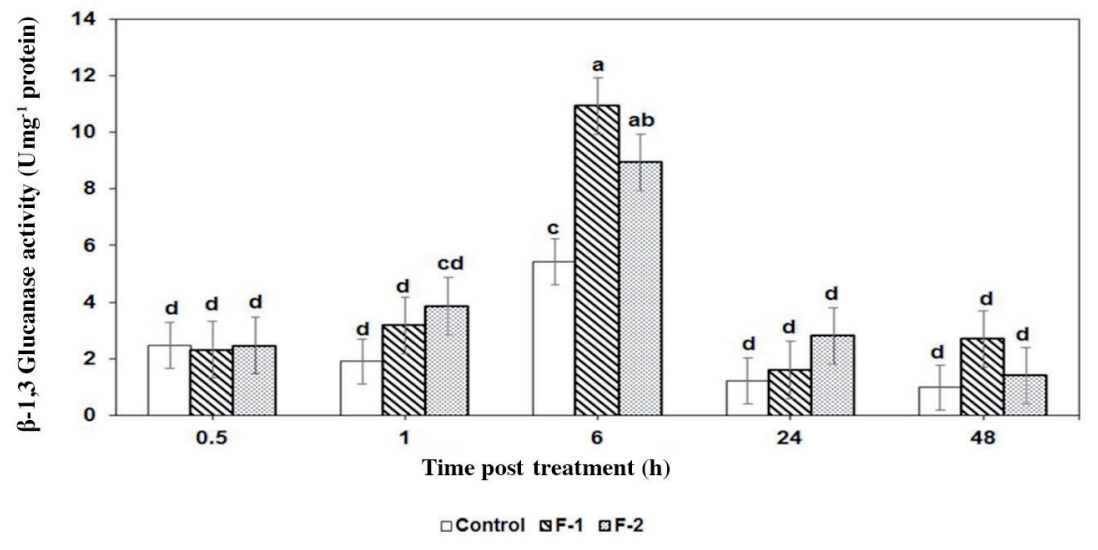


Figure 4. Effect of two fragments of potato rhamnogalacturonan I (RGI) (F-1 and F-2) on chitinase activity in tomato fruits stored for $48 \mathrm{~h}$ at $20{ }^{\circ} \mathrm{C}$ and $85 \% \mathrm{RH}$. Each point represents the mean of three fruits and vertical lines the standard deviation. Different letters indicate significant differences $(\mathbf{p} \leq \mathbf{0 . 0 5})$.

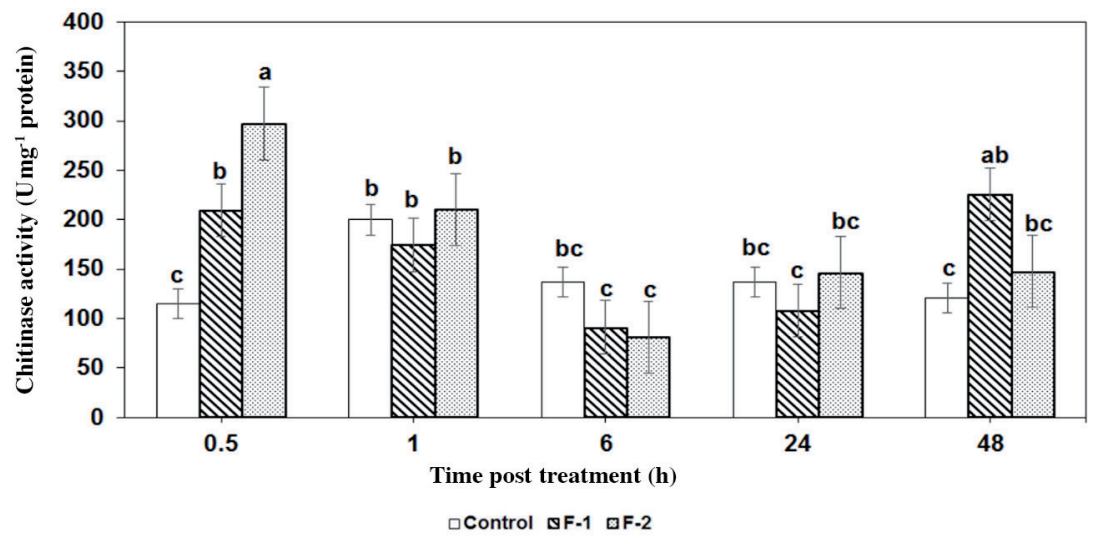

Figure 5. Changes in peroxidase activity in tomato fruits exposed to two fragments of potato rhamnogalacturonan I (RGI) (F-1 and F-2) and stored during $48 \mathrm{~h}$ at $20{ }^{\circ} \mathrm{C}$, and $85 \% \mathrm{RH}$. Each point represents the mean of three fruits and vertical lines the standard deviation. Different letters indicate significant differences $(\mathbf{p} \leq \mathbf{0 . 0 5})$.

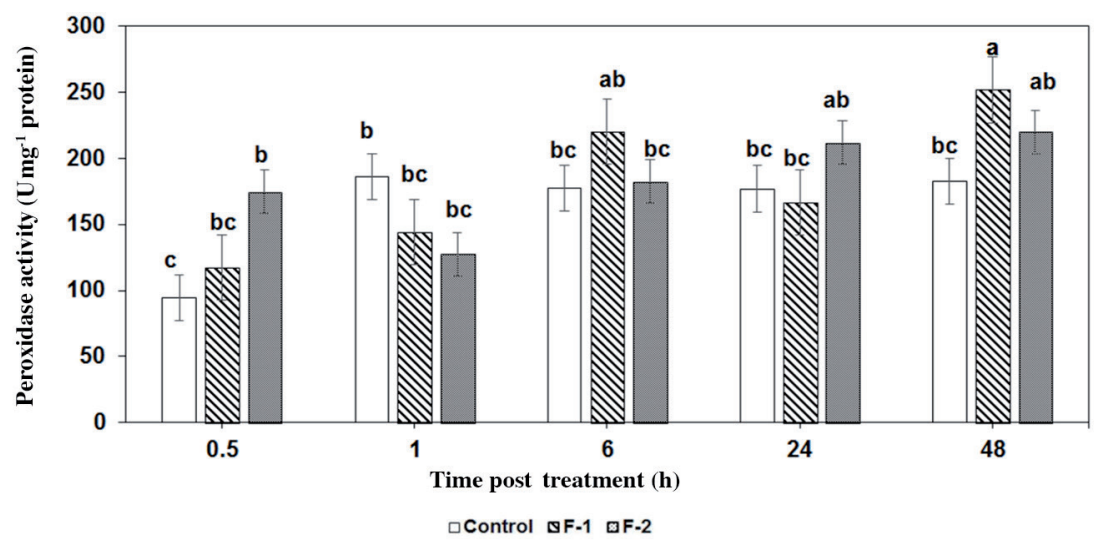

\section{DISCUSSION}

Potato RGI (RGI nf) was characterized according to its physical properties and its chemical composition. The results of this characterization reveal that this polymer presents physical and chemical characteristics that suggest a structure formed by a long linear chain with repeated units of rhamnose and galacturonic acid (ratio 12:1), together with neutral sugars of which galactose was predominant. In addition, the FT-IR spectrum suggests that RGI nf is demethyl-esterified. These results coincide with those reported by Voragen et al. (2009), who stated that the RGI of plant cells is not methylesterified. In addition, the RGI analyzed was clearly polydisperse with apparent molecular weight in a broad range (400$50 \mathrm{kDa}$ ). The elution pattern of the polymer shows that this polymer comprised two populations of polysaccharides that differed considerably in hydrodynamic volumes. These results agree to those reported by Khodaei and Karboune (2013), who registered an estimated molecular weight distribution of 50 to $500 \mathrm{kDa}$ for potato RGI.

The RGI fragments obtained by enzymatic degradation of the rhamnogalacturonan lyase presented lower Mw and galacturonic acid content; while the content of neutral sugars was increasing. The enzymatic degradation by RG lyase occurs at specific sites within the main chain of potato RGI. A reduction of galacturonic acid (AGal, $-42.6 \%$ ), and also in the increase of rhamnose (Ram, $+2.3 \%)$, and galactose $(\mathrm{Gal},+2.4 \%)$ occurs in all fragments. These results agree with those reported by Boudart et al. (1998), Obro et al. (2004), and Byg et al. (2012). In these studies, the authors used acid hydrolysis and subsequently applied enzymes such as galactanases, arabinases, and polygalacturonases to obtain pectic fragments of RGI, observing the decrease of galacturonic acid and an increase of neutral sugars. 
The content of AGal, Ram, and Gal in the RGI of potato nf is similar to that reported by Boudart et al. (1998), who obtained purified pectin fragments of RGI derived from bean plants, in which the weight percentage were 61.9, 3.9, and 19.6, respectively. However, the content of these sugars in other RGI potato studies varies considerably due to the different methods of extraction, purification and the type or variety of potato. In this sense, Byg et al. (2012) reported in potato pulp the weight percentage of sugars AGal, Ram, and Gal of 10.27, 4.51, and 73.35, respectively. In contrast, Khodaei and Karboune (2013) found a weight percentage of AGal similar to Gal (44.3 and 31.8, respectively), which attributed to the applied alkali treatment.

There is evidence that components of the cell wall contribute to plant disease resistance. One of these is the RGI, which the biological activity of its fragments had been reported in vegetative tissue and cells, but not in fruits. From the data of the present study, it is clear that the RGI fragments generated by rhamnogalacturonan lyase induce an increase in the activity of the PR proteins in tomato fruit, such as $\beta-1,3$-glucanase, chitinase, and peroxidase. These results agree with those reported by Boudart et al. (1998), who found an increase of $\beta$-1,3-glucanase by the application of pectic fragments. The authors stated that these fragments contained a higher proportion of galactose, arabinose, and rhamnose, suggesting the presence of side chains in RGI. In a similar study, Dinand et al. (1997) applied two RGI tetrasaccharides to $R$. fruticosus cells and protoplasts at the concentration of $30 \mathrm{nM}$. The authors found an increase in the activity of $\beta-1,3$-glucanase after incubation for $15 \mathrm{~min}$. The experimental data generated in this work and data from the literature suggest that the fragments derived from RGI by the action of RG lyase can act as signaling molecules in plants. This signaling could occur when the fragments interact with receptors called cell wall-associated kinases (WAKs) that can bind to pectins, including homogalacturonans, oligogalacturonides, and rhamnogalacturonans I and II (Kohorn et al., 2009; Trouvelot et al., 2014). The common characteristic of these molecules is the presence of galacturonic acid (AGal), therefore the existence of this compound in the chains of the RGI fragments could generate the signaling that caused the increase in the enzymatic activity of $\beta-1,3$-glucanase (Kohorn and Kohorn, 2012).

In addition, an early response of enzymatic activity was observed in tomato fruits exposed to RGI fragments. According to studies reported by Brutus et al. (2010), Heil et al. (2012), and Shinya et al., (2006), the plant responses to biotic or abiotic stresses could be observed through different molecules (metabolites, proteins or transcripts), and these responses could occurs during the first hours after the treatment. In fruits, Wang et al. (2011) applied oligandrin protein in tomato fruit, observing an induction in the expression of PR2 ( $\beta$-1,3-glucanase) and PR3 (chitinase) genes at $24 \mathrm{~h}$ post-treatment; and in the PR6 gene (protease inhibitor) at $8 \mathrm{~h}$ post-treatment. In the present study, the increase in enzymatic activity of $\beta$-1,3-glucanase was observed after $6 \mathrm{~h}$ of the fragments application. But Boudart et al. (1998) showed that this enzymatic activity was induced at $12 \mathrm{~h}$ and decreased at $48 \mathrm{~h}$ of treatment with pectic fragments (in resistant bean plants). The highest induction of chitinase activity occurred 30 min after we applied the F-2 treatment. This response may be because this fragment is the lowest in molecular weight, viscosity and hydrodynamic radius (Table 1), as well as its content of neutral sugars and AGal is more significant ( $\operatorname{Ram} 8 \%, \mathrm{Gal} 13 \%$, and AGal 45\%, respectively). It is important to mention that the results of the present study are the first experimental evidence that shows that the fragments of the RGI of potato induce an increase in the level of activity of chitinase in fruits.

\section{CONCLUSIONS}

The rhamnogalacturonan (RG) I potato fragments produced by the degradation of the enzyme RG lyase, with molecular weights of 20 and $16 \mathrm{kDa}$ and an average intrinsic viscosity by weight of 27 and $26 \mathrm{~mL} \mathrm{~g}^{-1}$, respectively, increased the levels of the activity of the enzymes $\beta-1,3$-glucanase, chitinase, and peroxidase in tomato fruits.

\section{ACKNOWLEDGEMENTS}

The authors are grateful to Consejo Nacional de Ciencia y Tecnología for the financial support to carry out this study with the grant number 177248. Also, to the Centro de Investigación en Alimentación y Desarrollo, A.C. (CIAD, A.C.) from Hermosillo, Sonora, Mexico, for the financial and facilities support. 


\section{REFERENCES}

Blakeney, A.B., Harris, P.J., Henry, R.J., and Stone, B.A. 1983. A simple and rapid preparation of alditol acetates for monosaccharide analysis. Carbohydrate Research 113(2):291-299.

Boudart, G., Lafitte, C., Barthe, J.P., Frasez, D., and Esquerré-Tugayé, M.T. 1998. Differential elicitation of defense responses by pectic fragments in bean seedlings. Planta 206(1):86-94.

Bradford, M.M. 1976. A rapid and sensitive method for the quantitation of microgram quantities of protein utilizing the principle of protein-dye binding. Analytical Biochemistry 72(1-2):248-254.

Brutus, A., Sicilia, F., Macone, A., Cervone, F., and De Lorenzo, G. 2010. A domain swap approach reveals a role of the plant wall-associated kinase 1 (WAK1) as a receptor of oligogalacturonides. Proceedings of the National Academy of Sciences of the United States of America 107(20):9452-9457.

Byg, I., Diaz, J., Ogendal, L.H., Harholt, J., Jorgensen, B., Rolin, C., et al. 2012. Large-scale extraction of rhamnogalacturonan I from industrial potato waste. Food Chemistry 131(4):1207-1216.

Caffall, K.H., and Mohnen, D. 2009. The structure, function, and biosynthesis of plant cell wall pectic polysaccharides. Carbohydrate Research 344(14):1879-1900.

Camejo, D., Marti, M.C., Olmos, E., Torres, W., Sevilla, F., and Jiménez, A. 2012. Oligogalacturonides stimulate antioxidant system in alfalfa roots. Biologia Plantarum 56(3):537-544.

Chaplin, M. 1986. Monosaccharides. Carbohydrate analysis: A practical approach. p. 1-36. In Chaplin, M.K., and Kennedy, J.F. (eds.) IRL Press, Oxford, UK.

Cota, I., Troncoso-Rojas, R., Sotelo-Mundo, R., Sánchez-Estrada, A., and Tiznado-Hernández, M.E. 2007. Chitinase and $\beta$-1, 3-glucanase enzymatic activities in response to infection by Alternaria alternata evaluated in two stages of development in different tomato fruit varieties. Scientia Horticulturae 112(1):42-50.

Denoux, C., Galletti, R., Mammarella, N., Gopalan, S., Werck, D., De Lorenzo, G., et al. 2008. Activation of defense response pathways by OGs and Flg22 elicitors in Arabidopsis seedlings. Molecular Plant 1(3):423-445.

Dinand, E., Excoffier, G., Lienart, Y., and Vignon, M.R. 1997. Two rhamnogalacturonide tetrasaccharides isolated from semiretted flax fibers are signaling molecules in Rubus fruticosus L. cells. Plant Physiology 115(2):793-801.

FAOSTAT. 2017. FAOSTAT Database. Food and Agriculture Organization of the United Nations (FAO), Rome, Italy. Available at http://faostat3.fao.org/browse/Q/QC/E.

Flurkey, W.H., and Jen, J.J. 1978. Peroxidase and polyphenol oxidase activities in developing peaches. Journal of Food Science 43(6): 1826-1828.

Harholt, J., Suttangkakul, A., and Scheller, H.V. 2010. Biosynthesis of pectin. Plant Physiology 153:384-395.

Heil, M., Ibarra-Laclette, E., Adame-Álvarez, R.M., Martínez, O., Ramirez-Chávez, E., Molina-Torres, J., et al. 2012. How plants sense wounds: damaged-self recognition is based on plant-derived elicitors and induces octadecanoid signaling. PLoS ONE 7(2):e30537.

Ho, G.T.T., Zou, Y.F., Wangensteen, H., and Barsett, H. 2016. RG-I regions from elderflower pectincs substituted on GalA are strong immunomodulators. International Journal of Biological Macromolecules 92:731-738.

Khodaei, N., and Karboune, S. 2013. Extraction and structural characterisation of rhamnogalacturonan I-type pectic polysaccharides from potato cell wall. Food Chemistry 139(1):617-623.

Kohorn, B.D., Johansen, S., Shishido, A., Todorova, T., Martinez, R., Defeo, E., et al. 2009. Pectin activation of MAP kinase and gene expression is WAK2 dependent. The Plant Journal 60(6):974-982.

Kohorn, B.D., and Kohorn, S.L. 2012. The cell wall-associated kinases, WAKs, as pectin receptors. Frontiers in Plant Science $3: 88$.

McKie, V.A., Vincken, J.P., Voragen, A.G., Van den Broek, L.A., Stimson, E., and Gilbert, H.J. 2001. A new family of rhamnogalacturonan lyases contains an enzyme that binds to cellulose. Biochemical Journal 355(1):167-177.

Martínez-López, A.L., Carvajal-Millán, E., Miki-Yoshida, M., Alvarez-Contreras, L., Rascón-Chu, A., Lizardi-Mendoza, J., et al. 2013. Arabinoxylan microspheres: Structural and textural characteristics. Molecules 18(4):4640-4650.

Morales-Ortega, A., Carvajal-Millan, E., López-Franco, Y., Rascón-Chu, A., Lizardi-Mendoza, J., Torres-Chavez, P., et al. 2013. Characterization of water extractable arabinoxylans from a spring wheat flour: rheological properties and microstructure. Molecules 18:8417-8428.

Morris, G.A., Ralet, M.C., Bonnin, E., Thibault, J.F., and Harding, S.E. 2010. Physical characterisation of the rhamnogalacturonan and homogalacturonan fractions of sugar beet (Beta vulgaris) pectin. Carbohydrate Polymers 82(4):1161-1167.

Moss, M.O. 2008. Fungi, quality and safety issues in fresh fruits and vegetables. Journal of Applied Microbiology 104:1239-1243

Obro, J., Harholt, J., Scheller, H.V., and Orfila, C. 2004. Rhamnogalacturonan I in Solanum tuberosum tubers contains complex arabinogalactan structures. Phytochemistry 65(10):1429-1438.

Osorio, S., Bombarely, A., Giavalisco, P., Usadel, B., Stephens, C., Aragüez, I., et al. 2011. Demethylation of oligogalacturonides by FAPEI in the fruits of the wild strawberry Fragaria vesca triggers metabolic and transcriptional changes associated with defence and development of the fruit. Journal of Experimental Botany 62(8):2855-2873. 
Pandey, D., Rajendran, S.R.Ch.K., Gaur, M., Sajeesh, P.K., and Kumar, A. 2016. Plant defense signaling and responses against necrotrophic fungal pathogens. Journal of Plant Growth Regulation 35:1159-1174.

Ribas, A.D.R., Spolti, P., Del Ponte, E.M., Donato, K.Z., Schrekker, H., and Fuentefria, A.M. 2016. Is the emergence of fungal resistance to medical triazoles related to their use in the agroecosystems? A mini review. Brazilian Journal of Microbiology 47:793-799.

Sánchez-Estrada, A., Tiznado-Hernández, M.E., Ojeda-Contreras, A.J., Valenzuela-Quintanar, A.I., and Troncoso-Rojas, R. 2009. Induction of enzymes and phenolic compounds related to the natural defence response of netted melon fruit by a bioelicitor. Journal of Phytopathology 157:24-32.

Sénéchal, F., Wattier, C., Rustérucci, C., and Pelloux, J. 2014. Homogalacturonan-modifying enzymes: structure, expression, and roles in plants. Journal of Experimental Botany 65(18):5125-5160.

Shinya, T., Ménard, R., Kozone, I., Matsuoka, H., Shibuya, N., Kauffmann, S., et al. 2006. Novel ß-1,3-, 1,6-oligoglucan elicitor from Alternaria alternata 102 for defense responses in tobacco. FEBS 276:2421-2431.

Silva, I.R., Jers, C., Meyer, A.S., and Mikkelsen, J.D. 2016. Rhamnogalacturonan I modifying enzymes: an update. New Biotechnology 33(1):41-54.

Sousa, A.G., Nielsen, H.L., Armagan, I., Larsen, J., and Sorensen, S.O. 2015. The impact of rhamnogalacturonan-I side chain monosaccharides on the rheological properties of citrus pectin. Food Hydrocolloids 47:130-139.

Taylor, K.A. 1993. A colorimetric method for the quantitation of galacturonic acid. Applied Biochemistry and Biotechnology 43(1):51-54.

Trouvelot, S., Héloir, M.C., Poinssot, B., Gauthier, A., Paris, F., Guillier, C., et al. 2014. Carbohydrates in plant immunity and plant protection: roles and potential application as foliar sprays. Frontiers in Plant Science 11(5):1-14.

Voragen, A.G., Coenen, G.J., Verhoef, R.P., and Schols, H.A. 2009. Pectin, a versatile polysaccharide present in plant cell walls. Structural Chemistry 20(2):263-275.

Wang, A., Lou, B., Xu, T., and Lin, Ch. 2011. Defense responses in tomato fruit induced by oligandrin against Botrytis cinerea . African Journal of Biotechnology 10(22):4596-4601.

Wu, X., and Mort, A. 2014. Structure of a rhamnogalacturonan fragment from apple pectin: implications for pectin architecture. International Journal of Carbohydrate Chemistry 2014. Article ID 347381. 